Published in final edited form as:

Gastroenterology. 2008 August ; 135(2): 468-476. doi:10.1053/j.gastro.2008.04.018.

\title{
Donor Morbidity After Living Donation for Liver Transplantation
}

\author{
RAFIK M. GHOBRIAL ${ }^{*}$, CHRIS E. FREISE ${ }^{\ddagger}$, JAMES F. TROTTER $^{\S}$, LAN TONG ${ }^{\|}$, AKINLOLU \\ O. OJOI, JEFFREY H. FAIR ${ }^{\#}$, ROBERT A. FISHER ${ }^{\star \star}$, JEAN C. EMOND市, ALAN J. \\ KOFFRON§§, TIMOTHY L. PRUETT||l|, KIM M. OLTHOFFII, and the A2ALL Study Group \\ *Department of Surgery, University of California Los Angeles, Los Angeles, California \\ ¥Department of Surgery, University of California San Francisco, San Francisco, California \\ $\S$ Department of Medicine, University of Colorado, Denver, Colorado \\ IDepartment of Surgery, University of Michigan, Ann Arbor, Michigan \\ IDepartment of Internal Medicine, University of Michigan, Ann Arbor, Michigan \\ \#Department of Surgery, University of North Carolina, Chapel Hill, North Carolina \\ ${ }^{* *}$ Department of Surgery, Medical College of Virginia Hospitals, Virginia Commonwealth \\ University, Richmond, Virginia \\ ¥‡Department of Surgery, University of Columbia Medical Center, New York, New York \\ $\S \S$ Department of Medicine, Northwestern University Medical School, Chicago, Illinois \\ IIIIDepartment of Medicine, University of Virginia, Charlottesville, Virginia \\ II'Department of Surgery, University of Pennsylvania, Philadelphia, Pennsylvania
}

\begin{abstract}
Background \& Aims-Reports of complications among adult right hepatic lobe donors have been limited to single centers. The rate and severity of complications in living donors were investigated in the 9-center Adult-to-Adult Living Donor Liver Transplantation Cohort Study (A2ALL).
\end{abstract}

Methods-A retrospective observational study design was used. Participants included all potential living donors evaluated between 1998 and 2003. Complication severity was graded using the Clavien scoring system.

Results-Of 405 donors accepted for donation, 393 underwent donation, and 12 procedures were aborted. There were 245 donors (62\%) who did not experience complications; 82 (21\%) had 1 complication, and $66(17 \%)$ had 2 or more. Complications were scored as grade 1 (minor; $n=106$, $27 \%$ ), grade 2 (potentially life threatening; $\mathrm{n}=103,26 \%$ ), grade 3 (life threatening; $\mathrm{n}=8,2 \%$ ), and grade 4 (leading to death; $\mathrm{n}=3,0.8 \%$ ). Common complications included biliary leaks beyond postoperative day $7(n=36,9 \%)$, bacterial infections $(n=49,12 \%)$, incisional hernia $(n=22$, $6 \%)$, pleural effusion requiring intervention $(\mathrm{n}=21,5 \%)$, neuropraxia $(\mathrm{n}=16,4 \%)$, reexploration $(\mathrm{n}=12,3 \%)$, wound infections $(\mathrm{n}=12,3 \%)$, and intraabdominal abscess $(\mathrm{n}=9,2 \%)$. Two donors

Address requests for reprints to: Rafik M. Ghobrial, MD, PhD, c/o A2ALL Study—Data Coordinating Center, 315 W. Huron, Suite 240, Ann Arbor, MI 48103-4262. a2all-dcc@umich.edu; fax: 734-996-6620.

Conflicts of interest: No conflicts of interest exist.

Presented in part at the World Transplant Congress, Boston, Massachusetts, July 2006.

This is publication number 9 of the Adult-to-Adult Living Donor Liver Transplantation Cohort Study. 
developed portal vein thrombosis, and 1 had inferior vena caval thrombosis. Fifty-one (13\%) donors required hospital readmission, and $14(4 \%)$ required 2 to 5 readmissions.

Conclusions-Adult living liver donation was associated with significant donor complications. Although most complications were of low-grade severity, a significant proportion were severe or life threatening. Quantification of complication risk may improve the informed consent process, perioperative planning, and donor care.

The rising demand for orthotopic liver transplantation in the United States has continued to outpace the availability of deceased donor organs. ${ }^{1}$ Efforts to increase deceased liver donation have seen only modest successes. Rising rates of death on the waiting list led to the use of more innovative and risky approaches to transplantation, including reduced size and split liver organs and, more recently, living donors. ${ }^{2-7}$

Although potentially lifesaving for the recipient, living donor liver transplantation (LDLT) is a unique surgical procedure that subjects a healthy donor to a major surgical procedure without direct therapeutic benefits. ${ }^{8}$ This procedure is distinguished by the "double equipoise" that is imposed on both the donor and the recipient. ${ }^{9}$ LDLT was initially used in pediatric transplantation, employing left lobe or left lateral segment donation usually from an adult parent to his or her infant or small child. ${ }^{5}$ The ethics of exposing a healthy person to a risky surgical procedure in this situation was tempered by the relatively low rate of serious complications of left lobe or lateral segment resection and the emotional and personal benefits to a parent who makes a sacrifice for the health of his or her child.

Adult-to-adult LDLT was introduced almost a decade after LDLT for children and immediately increased concerns over donor safety. Adult-to-adult LDLT requires right or left lobe resection ( $\sim 30 \%-60 \%$ of the total liver mass) and usually depends on donation from a spouse or adult relative. The initial reports of high recipient successes and low donor morbidity rates ${ }^{10,11}$ led to rapid expansion of adult-to-adult LDLT, and, by 2001, this procedure accounted for more that 400 transplantations ( 10\% of all adult liver transplantations done in the United States that year). However, following a well-publicized donor death in $2002,{ }^{12}$ rates of adult-to-adult LDLT declined precipitously and have remained in the range of 250-300 per year subsequently. A major reassessment of the risks of right lobe liver donation has led to a more cautious approach to the use of this procedure.

Unfortunately, despite almost 10 years of experience with adult-to-adult LDLT in the United States, the risks of right lobe liver donation have not been well characterized. Most reports of complications of adult-to-adult LDLT are based on single transplant program experience. The rates of complications in these single center publications ranged from as low as $9 \%$ to as high as $67 \% .^{11,13-21}$ In a national survey from North America, the overall donor complication rate was reported to be only $10 \% .^{22}$ The lack of uniformity in defining complications and underreporting of technical complications, blood and blood product transfusions, and aborted donations all contribute to the lack of firm information about the risks of right lobe liver donation.

The Adult-to-Adult Living Donor Liver Transplantation (A2ALL) Cohort Study was initiated in 2002 as a cooperative research agreement funded by National Institutes of Health with 9 liver transplant centers and a data coordinating center. The A2ALL Study was developed with the specific aim of providing accurate information on the risks and benefits of adult-to-adult LDLT for both donors and recipients. Retrospective and prospective studies were initiated. For assessing complications, the uniform reporting of adverse outcomes of surgery proposed by Clavien et al ${ }^{23,24}$ was adopted. This classification and severity scoring system (Table 1) defined complications as unexpected events that were not inherent to the procedure. Originally developed for general surgical procedures, this system has been 
widely adopted in liver transplantation ${ }^{25}$ for standardization of reporting of complication rates for both donors and recipients. The current report analyzed complication rates among adult LDLT donors from the 9 transplant centers based on the A2ALL retrospective cohort.

\section{Patients and Methods}

\section{Study Population}

A full description of the donor evaluation process has recently been reported. ${ }^{26}$ Data were collected on all potential living liver donors who were evaluated between January 1, 1998, and February 28, 2003, at 9 US centers using a uniform comprehensive medical record review process. Of 1011 potential donors evaluated, 405 were accepted and went to the operating room with the intention to donate. There were 392 completed adult LDLT donations. Twelve procedures were aborted after the donor entered the operating room but prior to liver resection, and the resected right hepatic lobe of 1 additional donor was not transplanted into the intended recipient because of intraoperative death of the recipient. The median follow-up was 6 months (range, 5 days to 5.6 years).

\section{Definitions and Data Collection}

A structured data collection form based on the Clavien grading system was applied to the donation and postdonation experience of each donor. An electronic data entry system was used by the study coordinators at each site. Clavien severity scoring of complications was performed at the data coordinating center based on information provided by the sites.

Complications among donors whose procedures were completed were evaluated and graded where applicable. The intraoperative experiences and the complications of the donors with aborted procedures were examined and reported separately. Intraoperative hypotension, defined as systolic blood pressure $₫ 00 \mathrm{~mm} \mathrm{Hg}$, was not considered a complication because several of the participating centers purposefully allowed low blood pressures during the time of liver resection. On medical record/chart review, we were not able to determine whether the blood pressure was purposefully lowered or whether it was an inadvertent occurrence. However, hypotension was tested as a predictive covariate in statistical models associated with donor complications.

Residual left lobe weight according to preoperative imaging was used as an estimate of remnant liver volume where available. As an alternative, standard liver volume (SLV)*0.4 was used, based on excellent correlation between graft size and the formula estimate among cases in which both have been measured. ${ }^{27}$ For each center's LDLT procedures, a sequential case number was assigned to each adult-to-adult LDLT performed. Each adult-to-adult LDLT was then categorized as having occurred when the center was less experienced or more experienced based on case numbers $\mathcal{s} 0$ or $>20$, respectively. ${ }^{28}$

\section{Statistical Analysis}

Descriptive statistics are reported as ranges, means, standard deviations (SD), and proportions as appropriate. The Kaplan-Meier method was used to estimate the probability of rehospitalization after donation. Logistic regression analysis was used to assess the association of predictive variables with overall donor complications and with biliary complications. Results are presented as adjusted odds ratios. The covariates that were tested in both models included donor sex, age, race, ethnicity, body mass index (BMI), alkaline phosphatase, total bilirubin, donor relationship to recipient, evaluation year, transplant center, LDLT case number, center LDLT experience (more experience or less experience), number of bile ducts from the right lobe, intraoperative hypotension (yes/no), intraoperative blood transfusions, remnant liver size, and total duration of the donor operative procedure. 
All analyses were carried out using SAS 9.1 statistical software (SAS Institute Inc, Cary, NC).

\section{Human Subjects Protection}

The study was approved by the institutional review boards and privacy boards of the University of Michigan Data Coordinating Center and each of the 9 A2ALL transplant centers.

\section{Results \\ Donor Characteristics}

The characteristics of the 405 adults accepted for liver donation are shown in Table 2. All donors were adults below the age of 60 years. They were mainly non-Hispanic whites, and slightly over half were male. Sixty percent of donors were overweight or obese, the average BMI being $26\left(\mathrm{~kg} / \mathrm{m}^{2}\right)$. Two thirds of donors were biologically related to the recipient; adult sons and daughters were the most frequent relationships.

\section{Aborted Donations and Orphan Grafts}

A total of 13 of the 405 donor operations were aborted after arrival in the operating room. One potential donor declined donation in the operating room prior to induction of general anesthesia. In 1 case, the resection was completed, but the graft was not transplanted because of the intraoperative death of the recipient. Another donor underwent surgery with division of the parenchyma, but further division of bile ducts and vasculature was aborted because the intended recipient became unstable.

In the remaining 10 donor procedures, an incision was made, but the donor liver was not divided: in 4 instances, the liver was judged to be of poor quality because of steatosis, granulomas, or unspecified inadequacies; in 3 instances there were dense adhesions or small, aberrant bile ducts; and, in 3 instances, the discovery of intraoperative findings in the recipient contraindicated transplantation. There was no significant difference in the BMI between aborted and actual donors (mean, 28.5; range, 21.3-43.4 vs mean, 26.2; range, 17.4-41, respectively; $P=.09$ ).

Morbidity among the 12 aborted donations included 2 grade 1 complications and 1 intraoperative systolic blood pressure of $<100 \mathrm{~mm} \mathrm{Hg}$. In addition, the donor who underwent division of the parenchyma suffered a grade 2 complication because of bile leak, bacterial infection, and localized intraabdominal abscess. All donor complications after aborted donations were known to have resolved without permanent sequelae at the last follow-up.

\section{Donor Surgery}

Intraoperative features are shown in Table 3 for the 393 donors whose resection procedures were completed. The average remnant liver weight was $582 \mathrm{~g}$ (range, 180-1152 g). The operative time was available on $84 \%$ of donors and averaged 7.6 hours (range, 4-15.5 hours). Approximately one third of donors required blood transfusion, and, among these, most received 1 or 2 units of packed red blood cells. The high occurrence of systolic hypotension (22\%) reflected in part a decision to permit low intraoperative systemic blood pressure at some of the A2ALL transplant centers. 


\section{Donor Hospitalizations}

The average length of hospital stay for donation surgery was 7 days (range, 2-28 days), and half of the donors were hospitalized for at least 7 days (Table 4). After discharge, 51 donors (13\%) were rehospitalized at least once and 14 (4\%) on more than 1 occasion. Among 51 first rehospitalizations, two-thirds occurred within 90 days of the donation (Figure 1), and only 2 occurred more than 2 years ( 2.9 and 4.6 years) after donation. According to KaplanMeier analysis, the probabilities of rehospitalization were $10 \%$ and $23 \%$ at 3 months and 2 years postdonation, respectively.

\section{Overall Donor Morbidity and Severity}

The majority of donors $(n=245 ; 62 \%)$ did not suffer any complications, defined by the Clavien classification as any alteration from the ideal postoperative course with complete recovery. However, 148 donors (38\%) had a total of 220 complications (Table 5). Eightytwo donors $(21 \%)$ had 1 complication, $40(10.2 \%)$ had 2 complications, $16(4.1 \%)$ had 3 complications, and $10(2.6 \%)$ had 4 to 7 complications.

Approximately half of the complications were classified as grade 1 (minor, $\mathrm{n}=106 ; 48 \%$ ) and half as grade 2 (no lasting disability, $\mathrm{n}=103 ; 47 \%$ ). There were 8 grade 3 (lasting disability) and 3 grade 4 (death) complications. One patient died from infection and multiorgan system failure during the initial donation hospitalization, and the other 2 died more than a year after donation from drug overdose and suicide, respectively. A fourth death, which did not relate to a graded complication, was the result of a train accident. These deaths have been described in detail elsewhere. ${ }^{29}$

Forty-six percent of all complications and $45 \%$ of grade 3 or 4 complications occurred during the initial hospitalization. For the 5 donors with grade 3 or 4 complications during the initial hospitalization, the mean length of that hospitalization was 12.8 days (range, 7-22 days).

\section{Intraoperative Complications}

Intraoperative complications occurred in 10 donors (2.5\%). Reported intraoperative injuries included lacerations of the right hepatic vein and left portal vein and tears to the liver capsule. Other intraoperative complications, in 5 separate donors, included intraabdominal bleeding, portal vein clamp slippage with 500-mL blood loss, pneumothorax, hypotension, and a reaction to intraoperative blood transfusion. Another donor had transient immediate postoperative hypoxemia thought to be due to narcotic overdosage.

\section{Postoperative Complications}

The most common postoperative complications were infections (12.5\%), biliary leak (persistent leak beyond postoperative day 7) (9.2\%), and incisional hernia (5.6\%). These were also the most common grade 2 or greater complications. Liver decompensation or hepatic artery thrombosis did not occur. However, portal vein thrombosis occurred in 2 donors: one required operative thrombectomy with subsequent intensive care unit stay and 14 days of hospitalization, and the other was managed by radiologic intervention and medical treatment. Both events resolved within 3 months. One donor had inferior vena cava thrombosis that resolved with radiologic and medical management. No instances of myocardial infarction, heart failure, or deep venous thrombosis were observed, but there was a notable frequency of pleural effusions (5.3\%) that required thoracentesis or thoracostomy. Two surgical complications required treatment at the time of reexploration. A redundant remnant of the cystic duct was excised after causing a post-cholecystectomy syndrome. In the other case, a liver remnant that had rotated into the right upper quadrant was remobilized and repositioned. Neuropraxia occurred in 16 donors, 2 of whom had lasting disability. The 
most common psychologic complication was depression, which was usually identified well after the transplant hospitalization.

\section{Factors Associated With Donor Complications}

Univariable and multivariable analyses were employed using logistic regression to assess associations between donor and operative characteristics and the likelihood of complications. Among all the tested donor characteristics, only intraoperative blood transfusion was associated with a significantly higher risk of at least 1 complication among donors in both univariable and multivariable analyses using logistic regression (Table 6). Compared with donors who required no blood transfusions, those who received up to 1 unit had 2.7 times the odds of complications, and more than 1 unit of transfusion was associated with an odds ratio of 4.5 .

Significant predictors of biliary complications included higher predonation alkaline phosphatase levels and intraoperative blood transfusions in both univariable analyses and multivariable logistic regression. Donors in the highest quartile of alkaline phosphatase activity (86-197 IU/L) had more than 3 times the odds of developing biliary complications as those with lower activity (Table 6). Three of $8(37.5 \%)$ donors with predonation alkaline phosphatase greater than $150 \mathrm{IU} / \mathrm{L}$ (the highest laboratory upper limit of normal among the 9 centers) developed biliary complications. Compared with donors who did not require blood transfusion, those who received blood transfusion had 3 times the odds of developing biliary complications. As shown in Table 7, the predicted probability of any complication increased from 0.29 for no transfused blood to 0.65 for greater than 1 unit of blood. Similarly, the predicted probability of biliary complications increased with higher levels of alkaline phosphatase and blood transfusion. Duration of surgery was associated with neither the likelihood of any complications $(P=.45)$ nor of biliary complications $(P=.76)$.

We examined the rate of donor complications according to narrow categories of transplant center adult-to-adult LDLT experience (first 5 LDLTs, second 5 LDLTs, and so on). There was no obvious threshold or statistically significant trend in the occurrence of any complication $(P=.59)$, the total number of complications $(P=.97)$, or the occurrence of biliary complications $(P=.39)$ based on center adult-to-adult LDLT experience. However, the 3 grade 4 complications that led to death occurred during the early center experience (the first 20 adult-to-adult LDLT), even though the drug overdose and suicide occurred more than a year after the transplantation.

\section{Discussion}

It could be argued that adult-to-adult LDLT should not be considered an option for liver transplantation unless the risk to donors can be well-defined. Therefore, one of the principal aims of the A2ALL Study, and the main point of this report, was to identify the extent and severity of complications in adult living liver donors in an unbiased and standardized fashion. Incorporation of a widely used instrument for reporting complications greatly facilitated this effort. Across the 9 A2ALL centers, the overall complication rate was $38 \%$. Donor complication rates derived from single centers and surveys across the United States have generally been lower than this figure, but some have been higher. Similar variability has been seen in reports of single center experiences outside the United States. A report from Hong Kong of 100 donors indicated an overall major complication rate of $14 \%$ that was reduced to $6 \%$ in their second 50 patients. ${ }^{30}$ Minor complications decreased from $26 \%$ to $8 \%$. In a recent study from Taiwan, only 10 of 205 (4.9\%) donors suffered complications. ${ }^{19}$ Complications in 9 of 43 right lobe donors were reported from Kyoto. ${ }^{31}$ 
One possible explanation for the variation in complication rates could be transplant center and operative experience. Because the current study found no relationship between center experience and donor outcomes, this is unlikely to be the only explanation for rate variation. Furthermore, the few donor deaths that have been reported worldwide have generally occurred at experienced centers. ${ }^{32}$ An equally plausible explanation is that variation in complication rates across studies may reflect the lack of consistent definitions of surgical complications. Whereas some centers have included minor complications, others have only reported severe or life-threatening events. In our study, we defined complications as unexpected events that were not inherent to the procedure. ${ }^{22,23}$ Complications were further graded by severity to allow accurate comparisons. ${ }^{23,24}$ Although there was a more recent modification ${ }^{33}$ of this system, we utilized the earlier version based on ease of application, a larger volume of reported experience, and its recent adoption by the international liver community. ${ }^{34}$ Nearly half of the complications in the current study were grade 1 . Although the initial donor hospitalization was a relatively short 7 days, the cumulative readmission rate was $23 \%$ at 2 years. The majority of rehospitalizations occurred in the first 90 days, but 8 donors were rehospitalized beyond the first year.

The retrospective cohort design of the current study is an admitted shortcoming because it relied primarily on medical record abstraction for data collection. This may have resulted in incomplete capture of some relevant variables. As an example, we did not collect data on postoperative liver function tests because this information was not available at consistent intervals across the centers. Sites did not all measure the weight of the resected donor lobe, so, in some cases, calculated estimates were used. However, there were good correlations between the estimates and actual weights in instances in which the latter were available. Similarly, data on other issues such as pain and quality of life, although not available for the retrospective study, are being evaluated in the prospective component of the A2ALL Study that was initiated in 2004.

Previously dismissed as a rare event, donations were aborted in 3\% of the A2ALL cohort who went to the operating room. One of these patients underwent division of the liver parenchyma and subsequently developed a grade 1 bile leak. In an additional case, the liver became an "orphan" graft when the recipient died prior to engraftment. Such an event raises the ethical dilemma of giving an orphan graft to an unrelated and unplanned for recipient. ${ }^{35,36}$ Additionally, it is obvious that an aborted donation makes the donor susceptible to morbidity.

Certain individual complications are worth highlighting. Biliary complications have been one of the major concerns in adult LDLT donors and recipients. In this study, biliary complications were the second most common category of donor morbidity, occurring in nearly $10 \%$ of cases. The majority were grade 2 complications, which are considered, by definition, to be potentially life threatening or to have markedly prolonged intensive care unit stay or hospitalization. Another common complication was incisional hernia, affecting more than 5\% of donors. This rate is similar to that reported after other major abdominal surgical procedures but is perhaps surprising among healthy individuals undergoing elective surgery. Brachial plexus injury resulting in neuropraxia was also relatively common and resulted in lasting neuromuscular disability for 2 donors. This injury usually results from malpositioning on the operating table during a prolonged procedure. In fact, mean operative time was 455 minutes for those without neuropraxia and 530 minutes for those with neuropraxia $(P=.056)$. This can result in major functional disability, as well as permanent work disability for donors whose occupations depend on motor function of the arm.

An important contribution of the current study was the identification of preoperative and intraoperative factors significantly associated with complications after living liver donation. 
Intraoperative blood transfusion was the only variable that was significantly associated with the overall rate of complications $(P<.001)$ and 1 of only 2 predictors of biliary complications. Blood loss and ensuing transfusion may be surrogate markers for surgical complexity and/or the quality of the donor liver. Interestingly, the duration of the surgical procedure was not independently associated with a significantly higher likelihood of complications. Thus, meticulous time-consuming dissection may be a prudent approach for reducing donor complications. Our results are consistent with a reported study of 204 right and left lobe donors in which operative blood loss and number of segments resected were found to be significant independent predictors of complications. ${ }^{19}$ In addition to blood transfusion, we found that higher preoperative donor alkaline phosphatase was strongly associated with postdonation biliary complications $(P<.01)$. This association is intriguing and unexplained. From our retrospective observational cohort, it cannot be determined whether the alkaline phosphatase was largely liver derived or whether there might be unmeasured confounders that could have accounted for this observation. In fact, we are unaware of experimental or other observational data that would inform this finding. Because there is no other situation in medicine in which well-evaluated and presumably healthy individuals undergo removal of more than half of their liver, it is difficult to determine the implications of this finding. The correlation of alkaline phosphatase with liver biopsy and/or computed tomographic cholangiography findings may be examined in the prospective study. It is possible that modest alkaline phosphatase elevation suggests donor susceptibility to intraoperative ischemia, and the need for blood transfusion suggests possible exposure to an ischemic event, with the combination resulting in biliary complications. Our findings require validation and perhaps greater scrutiny of donors with high normal or slightly elevated alkaline phosphatase.

One important finding was the lack of an association between center LDLT experience and donor complications. This observation is in contrast to the corresponding A2ALL analyses of recipient outcomes and its predictors, in which a "learning curve" was identified and recipient outcomes improved after center experience with more than 20 adult-to-adult LDLT procedures. $^{28}$ The lack of a significant association between center experience and donor complications may indicate that surgical experience with hepatic resections outside the transplantation setting provides adequate training for the adult donor operation in LDLT but could also represent a type II error. Larger numbers of cases with more intensive follow-up of donors in the A2ALL prospective cohort study may yet identify other important predictors of complications that could be eliminated or ameliorated.

In summary, systematic data collection using a consistent and accepted classification system in this large multicenter study has documented the frequency and severity of complications among adult LDLT donors. This information should be used for the education and informed consent process for potential donors. Its greatest value may be realized well before transplantation, when a potential adult recipient is being considered for placement on the deceased donor waiting list and for LDLT. From the standpoint of management, meticulous surgical technique that prevents blood loss and the need for transfusion while avoiding hepatic ischemia may reduce the incidence of complication in adult donors. The association of postoperative biliary tract complications with alkaline phosphatase levels in the high normal range was an unanticipated finding and deserves further study.

\section{Acknowledgments}

This study was supported by National Institute of Diabetes \& Digestive \& Kidney Diseases through cooperative agreements (listed below). Additional support was provided by Health Resources and Services Administration (HRSA), and the American Society of Transplant Surgeons (ASTS). 
The following individuals were instrumental in the planning, conduct and/or care of patients enrolled in this study at each of the participating institutions as follows:

Columbia University Health Sciences, New York, NY (DK62483): PI: Jean C. Emond, MD; Co-PI: Robert S. Brown, Jr., MD, MPH; Study Coordinators: Rudina Odeh-Ramadan, PharmD; Scott Heese, BA

Northwestern University, Chicago, IL (DK62467): PI: Michael M.I. Abecassis, MD, MBA; Co-PI: Andreas Blei, MD; Study Coordinator: Patrice Al-Saden, RN, CCRC

University of Pennsylvania Health System, Philadelphia, PA (DK62494): PI: Abraham Shaked, MD, PhD; Co-PI: Kim M. Olthoff, MD; Study Coordinators: Mary Kaminski, PA-C; Mary Shaw, RN, BBA

University of Colorado Health Sciences Center, Denver, CO (DK62536): PI: James F. Trotter, MD; Co-PI: Igal Kam, MD; Study Coordinators: Carlos Garcia, BS

University of California Los Angeles, Los Angeles, CA (DK62496): PI: Rafik Mark Ghobrial, MD, PhD; CoPI: Ronald W. Busuttil, MD, PhD; Study Coordinator: Janet Mooney, RN, BSN

University of California San Francisco, San Francisco, CA (DK62444): PI: Chris E. Freise, MD, FACS; CoPI: Norah A. Terrault, MD; Study Coordinator: Dulce MacLeod, RN

University of Michigan Medical Center, Ann Arbor, MI (DK62498): PI: Robert M. Merion, MD; DCC Staff: Anna S.F. Lok, MD; Akinlolu O. Ojo, MD, PhD; Brenda W. Gillespie, PhD; Margaret Hill-Callahan, BS, LSW; Terese Howell, BS; Lan Tong, MS; Tempie H. Shearon, MS; Karen A. Wisniewski, MPH; Monique Lowe, BS

University of North Carolina, Chapel Hill, NC (DK62505): PI: Jeffrey H. Fair, MD; Study Coordinator: Carrie A. Nielsen, MA

University of Virginia (DK62484): PI: Carl L. Berg, MD; Co-PI: Timothy L. Pruett, MD; Study Coordinator: Jaye Davis, RN

Medical College of Virginia Hospitals, Virginia Commonwealth University, Richmond, VA (DK62531): PI: Robert A. Fisher, MD, FACS; Co-PI: Mitchell L. Shiffman, MD; Study Coordinators: Ede Fenick, RN; April Ashworth, RN

National Institute of Diabetes and Digestive and Kidney Diseases, Division of Digestive Diseases and Nutrition, Bethesda, MD: James E. Everhart, MD; Leonard B. Seeff, MD; Patricia R. Robuck, PhD; Jay H. Hoofnagle, MD

Supported in part by the National Institutes of Health (NIDDK grant numbers U01-DK62536, U01-DK62444, U01-DK62467, U01-DK62483, U01-DK62484, U01-DK62494, U01-DK62496, U01-DK62498, U01DK62505, U01-DK62531); the American Society of Transplant Surgeons; and the US Department of Health and Human Services, Health Resources, and Services Administration.

\title{
Abbreviations used in this paper
}

\author{
A2ALL Adult-to-Adult Living Donor Liver Transplantation Cohort Study \\ LDLT living donor liver transplantation
}

\section{References}

1. 2006 Annual Report of the U.S. Organ Procurement and Transplantation Network and the Scientific Registry for Transplant Recipients: Transplant Data 1996-2005. Department of Health and Human Services, Health Resources and Services Administration, Office of Special Programs, Division of Transplantation; Rockville, MD: United Network for Organ Sharing; Richmond, VA: Arbor Research Collaborative for Health; Ann Arbor, MI: 2007.

2. Bismuth H, Houssin D. Reduced-sized orthotopic liver graft in hepatic transplantation in children. Surgery. 1984; 95:367-370. [PubMed: 6367125]

3. Pichlmayr R, Ringe B, Gubernatis G, et al. Transplantation of a donor liver to 2 recipients (splitting transplantation) - a new method in the further development of segmental liver transplantation. Langenbecks Archiv fur Chirurgie. 1988; 373:127-130. [PubMed: 3287073]

4. Ghobrial RM, Yersiz H, Farmer D, et al. Predictors of survival after in vivo split liver transplantation: analysis of 110 consecutive cases. Ann Surg. 2000; 232:312-323. [PubMed: 10973381] 
5. Roberts JP, Hulbert-Shearon TE, Merion RM, et al. Influence of graft type on outcomes after pediatric liver transplantation. Am J Transpl. 2004; 4:373-377.

6. Hashikura Y, Makuuchi M, Kawasaki S, et al. Successful living related partial liver transplantation to an adult patient. Lancet. 1994; 43:1233-1234. [PubMed: 7909905]

7. Wachs M, Bak T, Karrer F, et al. Adult living donor liver transplantation using a right hepatic lobe. Transplantation. 1998; 66:1313-1316. [PubMed: 9846514]

8. Cotler SJ, McNutt R, Patil R, et al. Adult living donor liver transplant: preferences outside the medical community. Liver Transpl. 2001; 7:335-340. [PubMed: 11303293]

9. Cronin DC II, Millis JM, Siegler M. Transplantation of liver grafts from living donors into adultstoo much, too soon. N Engl J Med. 2001; 344:1633-1637. [PubMed: 11372018]

10. Marcos A, Fisher R, Ham J, et al. Right lobe living donor liver transplantation. Transplantation. 1999; 68:798-803. [PubMed: 10515380]

11. Marcos A, Ham J, Fisher R, et al. Single-center analysis of the first 40 adult-to-adult living donor liver transplants using the right lobe. Liver Transpl. 2000; 6:296-301. [PubMed: 10827229]

12. Miller C, Florman S, Kim-Schluger L, et al. Fulminant and fatal gas gangrene of the stomach in a healthy live liver donor. Liver Transpl. 2004; 10:1315-1319. [PubMed: 15376309]

13. Miller CM, Gondolesi GE, Florman S, et al. One hundred nine live donor liver transplants in adults and children: a single-center experience. Ann Surg. 2001; 3:301-312. [PubMed: 11524583]

14. Grewal HP, Shokouh-Amiri H, Vera S, et al. Surgical technique for right lobe adult living donor liver transplantation without veno-venous bypass or portocaval shunting with duct-to-duct biliary reconstruction. Ann Surg. 2001; 233:502-508. [PubMed: 11303131]

15. Pomfret EA, Pomposelli JJ, Lewis D, et al. Live donor adult liver transplantation using right lobe grafts. Arch Surg. 2001; 136:425-433. [PubMed: 11296114]

16. Trotter JF, Talamantes M, McClure M, et al. Right hepatic lobe donation for living donor liver transplantation: impact on donor quality of life. Liver Transpl. 2001; 7:485-493. [PubMed: 11443574]

17. Beavers KL, Sandler RS, Fair JH, et al. The living donor experience: donor health asessment and outcomes following living donor transplantation. Liver Transpl. 2001; 7:943-947. [PubMed: 11699029]

18. Ghobrial RM, Saab S, Lassman C, et al. Donor and recipient outcomes in right lobe adult living donor liver transplantation. Liver Transpl. 2002; 8:901-909. [PubMed: 12360431]

19. Ibrahim S, Chen CL, Lin CC, et al. Intraoperative blood loss is a risk factor for complications in donors after living donor hepatectomy. Liver Transpl. 2006; 12:950-957. [PubMed: 16721773]

20. Renz JF, Busuttil RW. Adult-to-adult living donor liver transplantation: a critical analysis. Sem Liver Dis. 2000; 20:411-424.

21. Beavers KL, Sandler RS, Shrestha R. Donor morbidity associated with right lobectomy for living donor liver transplantation to adult recipients: a systematic review. Liver Transpl. 2002; 8:110117. [PubMed: 11862585]

22. Brown RS Jr, Russo MW, Lai M, et al. A survey of liver transplantation from living adult donors in the United States. N Engl J Med. 2003; 348:818-825. [PubMed: 12606737]

23. Clavien PA, Sanabria JR, Strasberg S. Proposed classification of complications of surgery with examples of utility in cholecystectomy. Surgery. 1992; 111:518-526. [PubMed: 1598671]

24. Clavien PA, Sanabria JR, Mentha G, et al. Recent results of elective open cholecystectomy in a North American and a European center. Ann Surg. 1992; 216:618-626. [PubMed: 1466614]

25. Clavien PA, Camargo CA, Croxford R, et al. Definition and classification of negative outcomes in solid organ transplantation: application in liver transplantation. Ann Surg. 1994; 220:109-120. [PubMed: 8053733]

26. Trotter JF, Wisniewski KA, Terrault NA, et al. Outcomes of donor evaluation in adult-to-adult living donor liver transplantation. Hepatology. 2007; 46:1476-1484. [PubMed: 17668879]

27. Heinemann A, Wischhusen F, Puschel K, et al. Standard liver volume in the Caucasian population. Liver Transpl Surg. 1999; 5:366-368. [PubMed: 10477836]

28. Olthoff KM, Merion RM, Ghobrial RM, et al. Outcomes of 385 adult-to-adult living donor liver transplant reciopients. Ann Surg. 2005; 242:314-325. [PubMed: 16135918] 
29. Trotter JF, Adam R, Lo CM, et al. Documented deaths of hepatic lobe donors for living donor liver transplantation. Liver Transpl. 2006; 12:1485-1488. [PubMed: 16952175]

30. Lo CM, Fan ST, Liu CL, et al. Lessons learned from 100 right lobe living donors liver transplants. Ann Surg. 2004; 240:151-158. [PubMed: 15213631]

31. Fujita S, Kim ID, Uryhara K, et al. Hepatic grafts from live donors: donor morbiditry for 470 cases of live donation. Transpl Int. 2000; 13:333-339. [PubMed: 11052268]

32. Fan ST. Live donor liver transplantation in adults. Transplantation. 2006; 82:723-732. [PubMed: 17006315]

33. Dindo D, Demartines N, Clavien PA. Classification of surgical complications: a new proposal with evaluation in a cohort of 6336 patients and results of a survey. Ann Surg. 2004; 240:205-213. [PubMed: 15273542]

34. Barr ML, Belghiti J, Villamil FG, et al. A report of the Vancouver Forum on the care of the live organ donor lung, liver, pancreas, and intestine data and medical guidelines. Transplantation. 2006; 81:1373-1385. [PubMed: 16732172]

35. Nadalin S, Malago M, Tesa G, et al. "Hepar divisum" as a rare donor complication after intraoperative mortality of the recipient of an intended living donor liver transplantation. Liver Transpl. 2006; 12:428-434. [PubMed: 16498667]

36. Wachs M, Trotter J. The appropriate allocation of "orphan graft" in living donor liver transplantation. Liver Transpl. 2006; 12:361-362. [PubMed: 16498654] 


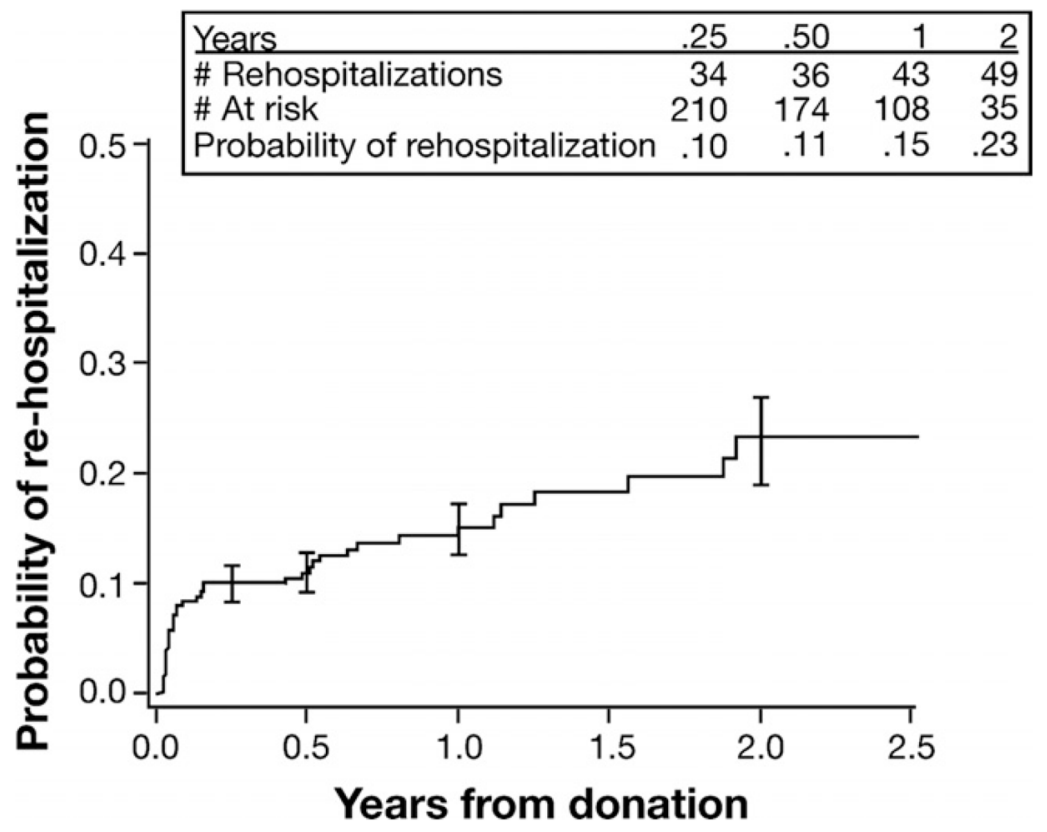

Figure 1.

Cumulative probability of donor rehospitalization after donation. Error bars are \pm 1 standard error. 
Table 1

\section{Clavien System for Classification of Negative Outcomes in General Surgery and Solid Organ Transplantation}

Grade 1 Any alteration from the ideal postoperative course, with complete recovery or which can be easily controlled and which fulfills the following general characteristics:

a. Not life threatening;

b. not requiring use of drugs other than immunosuppressants; analgesics; antipyretics; antiinflammatory agents; antiemetics; drugs required for urinary retention or lower urinary tract infection, arterial hypertension, hyperlipidemia, or transient hyperglycemia;

c. requiring only therapeutic procedures that can be performed at the bedside;

d. postoperative bleeding requiring $\mathfrak{3}$ units of blood transfusion; and

e. never associated with a prolongation of intensive care unit stay or total hospital stay to more than twice the median stay for the procedure in the population of the study.

Grade 2 Any complication that is potentially life threatening or results in intensive care unit stay $>5$ days, hospital stay $>4$ weeks for the recipient, but which does not result in residual disability or persistent disease

Grade 3 Any complication with residual or lasting functional disability or development of malignant disease

Grade 4 Complications that lead to retransplantation (grade 4a) or death (grade 4b)

NOTE. Adapted from references Brown et $\mathrm{al}^{22}$ and Clavien et al. ${ }^{23,24}$ 
Table 2

Characteristics of Accepted Adult Living Liver Donors

\begin{tabular}{|c|c|c|c|}
\hline Characteristic & $\mathbf{N}$ & Range & Mean (SD) or percent \\
\hline Age, y & 404 & $18-59$ & $37(9.6)$ \\
\hline \multicolumn{4}{|l|}{ Sex } \\
\hline Female & 182 & & 45 \\
\hline Male & 223 & & 55 \\
\hline \multicolumn{4}{|l|}{ Ethnicity } \\
\hline Hispanic/Latino & 68 & & 17 \\
\hline Non-Hispanic/non-Latino & 335 & & 83 \\
\hline Missing & 2 & & 1 \\
\hline \multicolumn{4}{|l|}{ Race } \\
\hline White & 366 & & 90 \\
\hline African American & 15 & & 4 \\
\hline Asian & 13 & & 3 \\
\hline Other & 9 & & 2 \\
\hline Missing & 2 & & 1 \\
\hline Height $(\mathrm{cm})$ & 397 & $150-203$ & $173(10.0)$ \\
\hline Weight (kg) & 402 & $43-141$ & $78(15.0)$ \\
\hline Body mass index $\left(\mathrm{kg} / \mathrm{m}^{2}\right)$ & 397 & $17-43$ & $26(3.9)$ \\
\hline$<20$ & 19 & & 5 \\
\hline$\geq 20$ to $<25$ & 136 & & 34 \\
\hline$\geq 25$ to $<30$ & 182 & & 45 \\
\hline$\geq 30$ & 60 & & 15 \\
\hline Missing & 8 & & 2 \\
\hline \multicolumn{4}{|l|}{ Relatedness to recipient } \\
\hline \multicolumn{4}{|l|}{ Biologically related } \\
\hline Parent & 9 & & 2 \\
\hline Child & 139 & & 34 \\
\hline Sibling & 92 & & 23 \\
\hline Other biological & 35 & & 9 \\
\hline \multicolumn{4}{|l|}{ Not biologically related } \\
\hline Spouse & 51 & & 13 \\
\hline Other nonbiological & 78 & & 19 \\
\hline Unknown/missing & 1 & & $<1$ \\
\hline Alkaline phosphatase $(I U / L)$ & 403 & $21-197$ & $74(26)$ \\
\hline 58 & 102 & & 25 \\
\hline$>58$ to 569 & 103 & & 26 \\
\hline$>69$ to $s 86$ & 98 & & 24 \\
\hline$>86$ to $\unlhd 97$ & 100 & & 25 \\
\hline Bilirubin $(I U / L)$ & 403 & $0.1-2.8$ & $0.72(0.4)$ \\
\hline$\$ 0.5$ & 134 & & 33 \\
\hline
\end{tabular}

Gastroenterology. Author manuscript; available in PMC 2013 August 01. 


\begin{tabular}{crcc}
\hline Characteristic & N & Range & Mean (SD) or percent \\
\hline$>0.5$ to $\unlhd .7$ & 123 & 31 \\
$>0.7$ to $\unlhd .9$ & 70 & 17 \\
$>0.9$ to $\mathcal{S} .8$ & 76 & 19 \\
\hline
\end{tabular}

NOTE. $\mathrm{N}=405$. Accepted donors were the donors who were accepted for liver donation and went to the operating room with the intention to donate. 
Table 3

Intraoperative and Postoperative Characteristics of Donors

\begin{tabular}{|c|c|c|c|}
\hline Characteristic & $\mathbf{N}$ & Range & Mean (SD) or percent \\
\hline Remnant liver weight $(g)^{a}$ & 388 & $180-1152$ & $582(156)$ \\
\hline$\geq 180$ to $\leq 480$ & 98 & & 25 \\
\hline$>480$ to 582 & 99 & & 25 \\
\hline$>582$ to $\varsigma 681$ & 95 & & 24 \\
\hline$>681$ to $\leq 152$ & 96 & & 24 \\
\hline Units of transfused blood & 387 & $0-4$ & $0.4(0.8)$ \\
\hline 0 & 267 & & 68 \\
\hline$>0$ to $\leq$ & 84 & & 21 \\
\hline$>1$ to $\underline{S}$ & 26 & & 7 \\
\hline$>2$ to $\leq 3$ & 6 & & 2 \\
\hline$>3$ to $\leq 4$ & 4 & & 1 \\
\hline \multicolumn{4}{|c|}{ Hypotension (<100 mm Hg systolic) } \\
\hline Yes & 88 & & 22 \\
\hline No & 288 & & 73 \\
\hline Missing & 17 & & 4 \\
\hline Operative time ( $\mathrm{min}$ ) & 329 & $236-930$ & $458(133)$ \\
\hline$\geq 236$ to $\leq 358$ & 83 & & 25 \\
\hline$>358$ to $\leq 424$ & 82 & & 25 \\
\hline$>424$ to 557 & 82 & & 25 \\
\hline$>557$ to $₫ 930$ & 82 & & 25 \\
\hline
\end{tabular}

NOTE. $\mathrm{N}=393$. Donors who successfully donated $(\mathrm{n}=392)$ and those with graft resected but not transplanted $(\mathrm{n}=1)$.

${ }^{a}$ Left lobe weight was obtained from preoperative imaging $(69 \%)$ or $0.4 \times$ donor standard liver volume (30\%) and was missing in $1 \%$. 
Table 4

Initial and Subsequent Hospitalizations of Donors

\begin{tabular}{lrcc}
\hline & N & Range & Mean (SD) or percent \\
\hline Initial donor hospitalization length of stay (day) & 391 & $2-28$ & $7.0(2.7)$ \\
$\geq 2$ to $<6$ & 98 & 25 \\
$\geq 6$ to $<7$ & 90 & 23 \\
$\geq 7$ to $<8$ & 91 & 23 \\
$\geq 8$ to $\_8$ & 112 & 28 \\
No. of rehospitalizations & & \\
0 & 342 & 87 \\
1 & 37 & 9 \\
2 & 8 & 2 \\
$3-5$ & 6 & 2 \\
\hline
\end{tabular}

NOTE. $N=393$. Donors who successfully donated $(n=392)$ and those with graft resected but not transplanted $(n=1)$. 


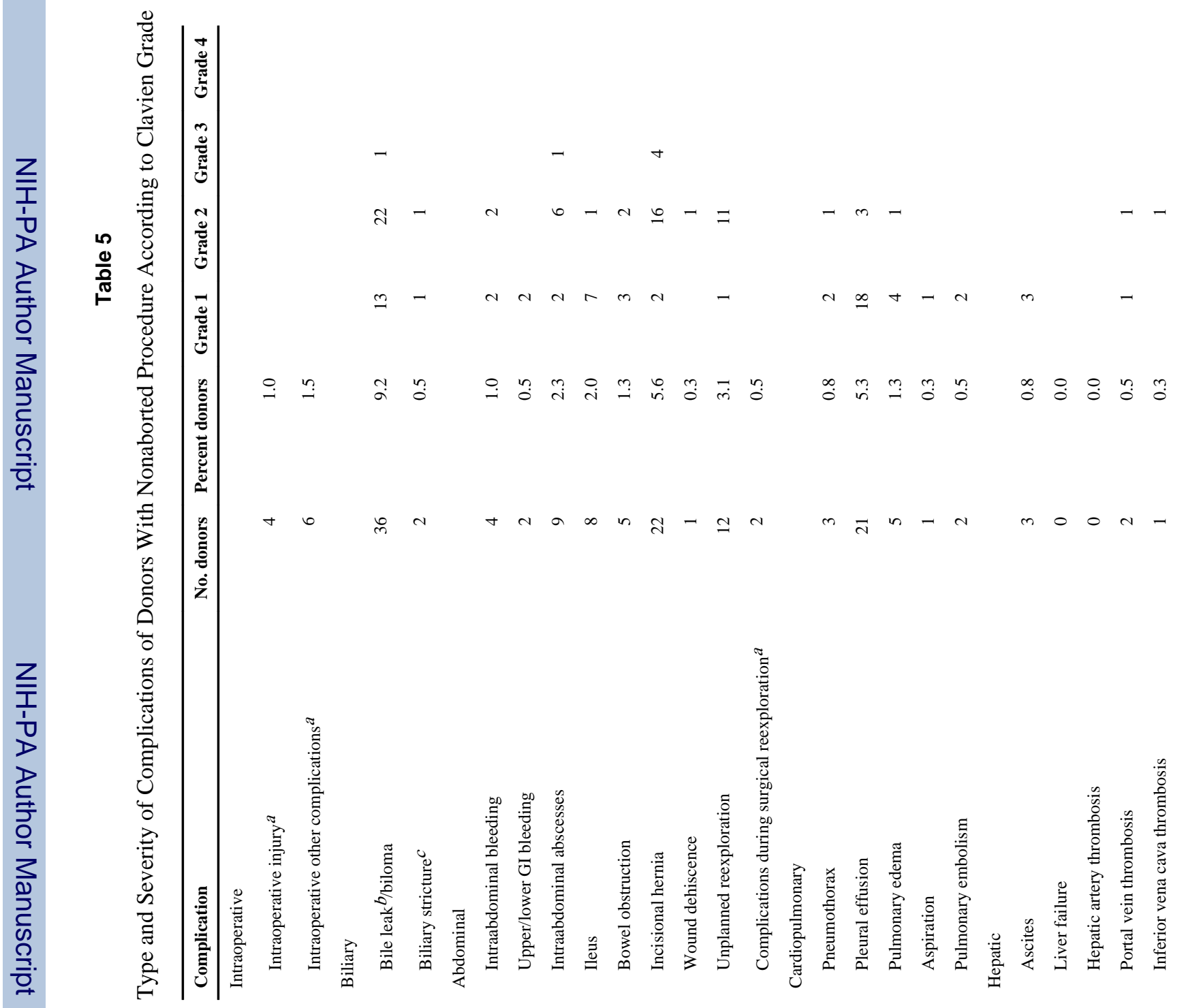

Gastroenterology. Author manuscript; available in PMC 2013 August 01. 


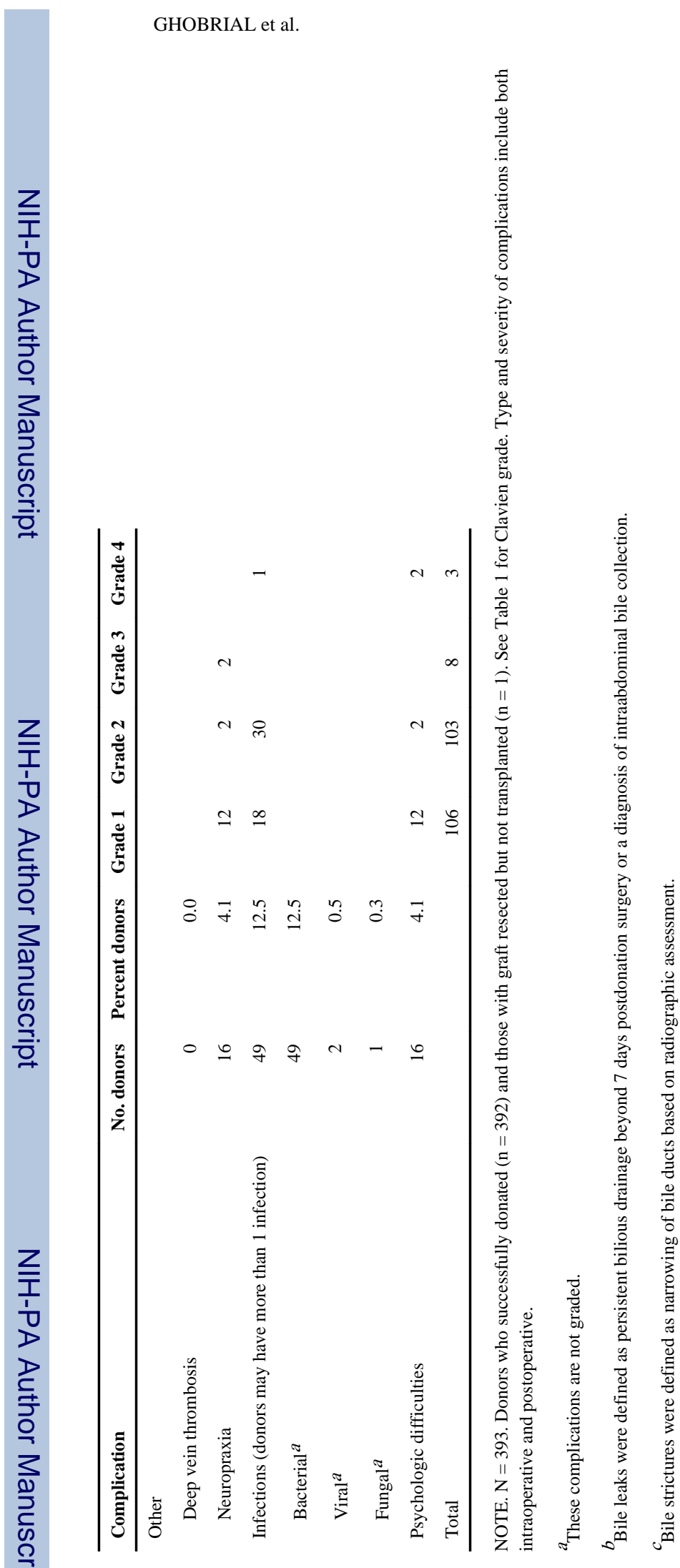

Gastroenterology. Author manuscript; available in PMC 2013 August 01. 
Table 6

Factors Associated With Any Complications or Biliary Complications After Donation

\begin{tabular}{|c|c|c|c|}
\hline Logistic regression model results & Odds ratio & 95\% Confidence interval & $P$ value \\
\hline \multicolumn{4}{|l|}{ Any complications ${ }^{a}$} \\
\hline \multicolumn{4}{|l|}{ Units of transfused blood } \\
\hline None & 1.0 & - & - \\
\hline 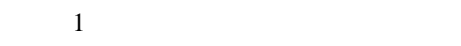 & 2.7 & $1.6-4.5$ & $<.001$ \\
\hline$>1$ & 4.5 & $2.2-9.4$ & $<.001$ \\
\hline \multicolumn{4}{|l|}{ Biliary complications $^{a}$} \\
\hline Alkaline phosphatase $(I U / L) \geq 86$ vs $<86$ & 2.99 & $1.48-6.03$ & .002 \\
\hline \multicolumn{4}{|l|}{ Units of transfused blood } \\
\hline None & 1.00 & - & - \\
\hline 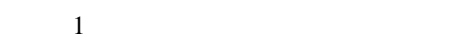 & 3.96 & $1.86-8.43$ & $<.001$ \\
\hline$>1$ & 3.32 & $1.19-9.29$ & .022 \\
\hline
\end{tabular}

${ }^{a}$ Variables tested and not significant included the following: donor age, sex, ethnicity, race, BMI, relationship to recipient, bilirubin, year of evaluation, LDLT experience, site, remnant liver volume, number of bile ducts from right lobe, hypotension during surgery, and length of intraoperative procedure. 
Table 7

Predicted Probabilities of Complications After Donation, by Predictive Factors

\begin{tabular}{lccc}
\hline & \multicolumn{3}{l}{ Units of red blood cells } \\
\cline { 2 - 4 } Predicted probabilities & None & $\mathbf{4}$ & $>\mathbf{1}$ \\
\hline Overall complications & 0.29 & 0.52 & 0.65 \\
Biliary complications & & & \\
$\quad$ Low alkaline phosphatase $(<86 I U / L)$ & 0.04 & 0.14 & 0.12 \\
$\quad$ High alkaline phosphatase $(\geq 86 I U / L)$ & 0.11 & 0.33 & 0.29 \\
\hline
\end{tabular}

